\title{
Students' perception toward the use of google classroom as an assessment media in EFL
}

\author{
Antika Rinanda ${ }^{1}$, Hery Yufrizal $^{2}$, Rafista Deviyanti ${ }^{3}$ \\ Universitas Lampung, Jl. Prof. Dr. SoemantriBrojonegoro No. 1, Bandar Lampung ${ }^{1,2,3}$ \\ 1'antikarinanda90@gmail.com
}

\begin{abstract}
The objectives of this research were to identify the students' perception of the use of online assessment on Google Classroom in EFL classrooms and to find out the students' challenges in doing online assessment in Google Classroom in EFL classrooms. The subjects were consisted of 45 English department students of Lampung University. A close-ended and an open-ended questionnaire were used to collect the data. The data from close-ended questionnaire was analyzed by using descriptive statistic on SPSS, while the data from the open-ended questionnaire was analyzed manually. The result of this study indicated that the students have a positive perception toward the use of online assessment in Google Classroom. It happened because the mean score of the questionnaire was 3.67 to 5.00. the range score indicates that the level of students' perception is on the high level. This study also found out that there are several challenges of the students faced when using online assessment in Google Classroom, those are; time, internet connection, the system problems and about the controller. Based on the research finding above, it be concluded that there are strengths and weaknesses toward the implementation o online assessment. Although as previously from the results of the data obtained that students have positive perceptions of the use of online assessment in Google Classroom, it does not mean that there are no difficulties from the students in doing the online assessment in Google Classroom.
\end{abstract}

Keywords: Google Classroom, online assessment, students' perception

\section{INTRODUCTION}

A long time ago, people have used technology as a tool to communicate each others. However, at the previous time technology is not as sophisticated as it is today. Technology nowadays has grown rapidly, people can access the internet and also can communicate with others easily. Technology is what separates us from the middle ages, indeed it is what separates us from the way we lived fifty thousand or more years ago. More than anything else technology creates our world.

Nowadays, students and teacher can also do teaching and learning activities online. Students can also learn through the internet where at this time learning materials are widely available on the internet. It is also help the teacher to look for teaching materials. Furthermore, the teachers can also do the process of teaching and learning outside the classroom by using the Learning Management System (LMS).

According to Diaz (2014) Learning Management System or can be said as (LMS) is one of the e-platforms that provides an online learning. LMSs are seen as information systems that are focused on the processes of communication, collaboration, and educational purposes. The LMS 
or Learning Management System can be used as a tool to conduct learning outside the classroom, it also helps the teacher to deliver material, give homework and others. For example, if the teacher is not able to attend to teach in the classroom, they can give the material through LMS, so that the students are still able to get the lesson from the teacher.

According to Kats (2010) teachers can make the process of teaching and learning to students outside the class by using LMS features that have been available. The LMS prepares a location for studying and teaching activities to happen within a seamless area, these frameworks permit instructive organizations on a deal with an expansive number for completely on the web or mixed (part internet furthermore a piece face-to-face) courses utilizing a normal interface.

Dabbagh\&Bannan-Ritland (2005) identifies the most common features of an LMS by categorizing them as pedagogical tools for content creation, communication, assessment, and administration. The examples of the LMS are Edmodo, Ruang Guru, Zenius, Google Classroom, Zoom and many more. One example of the application of the LMS to be studied in this research is Google Classroom application.

Perception is the association, identification, and the explanation of a sensation in order to figure a psychological illustration (Schacter, Gilbert, Wegner, 2009). In this study, the researcher wants to know the students perception of the use of online assessment in Google Classroom in their subject at EFL Classroom.

In another research, Sanli (2004) in her thesis "Students' Perceptions of Online Assessment: A Case Study". The aim of the study was to investigate students' perceptions of the use of CAA and to investigate the potential for using student feedback in the validation of assessment. The research was descriptive, using a paper-based survey and interview for the data collection. The previous study is aimed to investigate students' perceptions of the use of CAA and to investigate the potential for using student feedback in the validation of assessment. While, this current study focus on students' perception of the use of online assessment in Google Classroom, and this study also want to know the students' challenges not only the perception. The previous study did not use a Google Classroom while this current study uses a Google Classroom as an object of the research.

According to Chen and Hoshower (2003), the student's perception is really important for evaluating the teaching effectiveness. It is in line with Petegem (2007), the student perception is the important account to measure the learning outcomes, Freiberg and Stein stated that the students' perception is the solution of components and indicators in explaining the classroom conditions.

\section{METHODS}

The design if this study was classified as a survey research. In this case, the researcher wants to know the phenomenon that occurs outside or the field by using a survey method. The aim of this study was to get the information about students perception toward online assessment in the Google Classroom, therefore the researcher has used survey research to describe and interpret 
phenomenon. To answer both research questions, the researcher has used questionnaire as an instrument in this research. There were two kinds of questionnaire used in this research, that were open and close ended questionnaire. This study involved the students of English Department student UNILA (University of Lampung). They were selected randomly. The sample of this study was 45 students.

For collecting the data, the researcher has used questionnaire as the instrument. There were several procedures performed by researcher during the study. The several procedures were as follow:

1. The researcher prepared the instruments to collect the data.

2. Making the questionnaire. The questions in a questionnaire were about students' perception of online assessment in Google Classroom and the challenges in doing online assessment in Google Classroom.

3. After that, the questionnaire got the validity from the expert of this research.

4. In doing the research, the researcher has shared the questionnaire to the participants.

5. After getting the data, the researcher was analyzed the data and explained it descriptively with making the conclusion as the result of the research.

In this study, data have been collected by using close ended questionnaire. Then, after collecting the data, it was analyzed by using the SPSS (Statistical Package for Social Science) program. In analyzing the data, the researcher has used descriptive statistical analysis by searching for the data averages (mean) and levels (low mean rank, medium mean rank and high mean rank). The low mean appertains to low agreement. According to Likert scale, the range score of low mean rank is 1.00 to 2.33 , medium means is 2.34 to 3.66 , and high mean is 3.67 .

\section{RESULT AND DISCUSSION}

To find out about the students' perceptions of the use of online assessment in Google Classroom, this research administered questionnaires to 45 students. The questions in the questionnaire consist of both open and close-ended questions. The finding will be presented into two sections, namely students' perception of the use online assessment and the challenges in conducting online assessment. The result of the responses will be explained descriptively by using the SPSS. The following are the result of students' perceptions toward the use of online assessment and its challenges.

To know the students' perceptions of online assessment use in Google Classroom, this study asks the students to complete the close-ended questions in the questionnaire. This statement include a positive statements which are divided into four difference topics cover in the students' perception of online assessment use in Google Classroom, namely; the use of Google Classroom, the instruction in Google Classroom, assessment criteria, and the benefits of online assessment in Google Classroom. 
1. Categories of students' perception level

\begin{tabular}{|ccc|}
\hline No. & Level & Mean \\
\hline 1 & Low & $1.00-2.33$ \\
\hline 2 & Medium & $2.34-3.66$ \\
\hline 3 & High & $3.67-5.00$ \\
\hline
\end{tabular}

Based on the table above, it shows that the low mean rank consists of 1.00 until 2.33 mean, the medium mean rank consists of 2.34 until 3.66 and the high mean rank consists of 3.67 until 5.00 mean.

The first topic is about the statements that are related to the use of Google Classroom. There were six statements that are related to the use of Google Classroom. The six items in this category are; it is easy to register to Google Classroom (Q1), easy to use the features in Google Classroom (Q2), Google Classroom saves time (Q3), the Google Classroom is a fast and efficient way to get information (Q4), Google Classroom help students to learn the course (Q5), it is easy to take a quiz or test in Google Classroom (Q6). The results of the use of Google Classroom are as follow:

2. Level of the used of Google Classroom

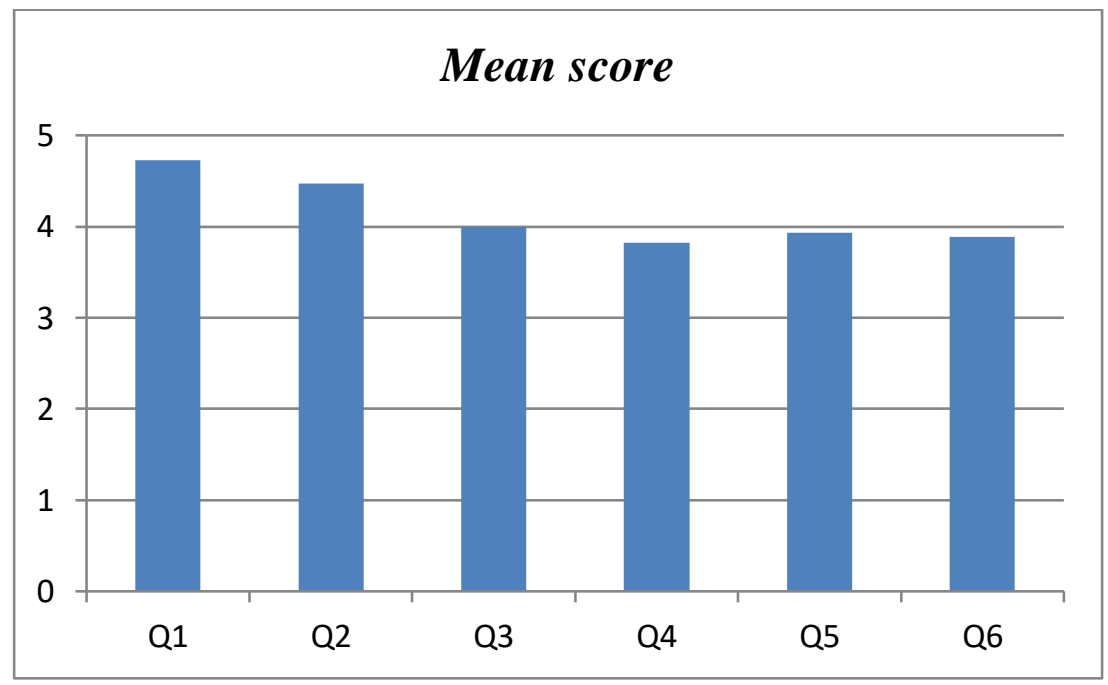

From the six statements above, it shows that Q1 and Q2 get the highest value among them. The mean score of Q1 "It easy to register to Google Classroom App" is 4.73 and Q2 "The features in Google Classroom App are easy to use" is 4.47. The result also shows that Q4 "The Google Classroom App is a fast and efficient way of getting information" get the lowest mean score among the six statements, the mean score is 3.82 . 
3. The uses of Google Classroom

\begin{tabular}{|lccc|}
\hline \multicolumn{1}{|c}{ Statement } & Mean & Std. Deviation & Level \\
\hline $\begin{array}{l}\text { It easy to register to Google } \\
\text { Classroom App. }\end{array}$ & 4.73 & .447 & High \\
\hline $\begin{array}{l}\text { The features in Google Classroom } \\
\text { App are easy to use. }\end{array}$ & 4.47 & .661 & High \\
\hline $\begin{array}{l}\text { Using the Google Classroom saves } \\
\text { time. }\end{array}$ & 4.00 & .826 & High \\
\hline $\begin{array}{l}\text { The Google Classroom App is a fast } \\
\text { and efficient way of getting } \\
\text { information. }\end{array}$ & 3.82 & 1.007 & High \\
\hline $\begin{array}{l}\text { Google Classroom App helps me to } \\
\text { learn the course. }\end{array}$ & 3.93 & .780 & High \\
\hline $\begin{array}{l}\text { It is easy to take a quiz or test in } \\
\text { Google Classroom. }\end{array}$ & 3.89 & .982 & High \\
\hline
\end{tabular}

Based on the result above, each question are get high score. It means that the students have positive perception toward the use of Google Classroom. Since Q1 get the highest score, it explains that $73.3 \%$ students are strongly agreed that register to Google Classroom is quite easy. It is also shows that about $53.5 \%$ students are strongly agreed that the features in Google Classroom are easy to use.

However, Q4 gets the lowest mean score among the six statements (mean = 3.82). Even though the mean score of the statement "the Google Classroom App is a fast and efficient way of getting information" is lowest among others, the mean score of $\mathrm{Q} 4$ is categorized high mean rank. This can be proved by seeing $26.6 \%$ of students choose strongly agree, $44.4 \%$ choose to agree, $13.3 \%$ choose neutral and $15.5 \%$ students choose to disagree with the statement.

\section{Discussion}

\section{Discussion of students' perception of online assessment}

The result of this study indicated that the students have a positive perception toward the use of online assessment in Google Classroom. When people have positive perception of a given behavior, they tend to view the process of the behavior in a positive way and develop a positive attitude towards it (Icekson and Pines, 2013). As Adams and Hamm (2013) said that students will work more effectively if they are familiar with technology and have a comprehending of the material. Therefore, the understanding of online technology is important to aid students' in doing online assessment in Google Classroom.

There are several reasons why the students have positive perception toward the use of online assessment. The first, they enjoy using the online assessment because the Google Classroom is very easy to use and they also have knowledge about technology before using the Google Classroom. The second reason why the students were interested using online assessment is 
online assessment is better than paper assessment. The presentation or features of Google Classroom are organized attractively and interactively visual appearance. On the contrary, paper assessment is monotonous.it does not have application to add media as in online assessment. Therefore, students feel enjoyable doing online assessment in Google Classroom. The third reason why the students enjoy doing the online assessment in Google Classroom is that the Google Classroom can save their time. By using Google Classroom, the students can do the test every time and everywhere as they are given the deadline by only working using the networking site. Moreover, using Google Classroom can also be operated everywhere without carrying any paper.

\section{Discussion of the challenges in online assessment}

Although as previously from the results of the data obtained that students have positive perceptions of the use of online assessment in Google Classroom, it does not mean that there are no difficulties from the students in doing the online assessment in Google Classroom. The findings of this research indicated that there are several challenges of the students faced when using online assessment in Google Classroom. From the results of the data obtained, there are; time, internet connection, the system problems and about the controller.

The first challenges are about the time, the students said that they must work quickly and accurately because it is limited by time, they cannot relax in doing online tests because they are chased by time and many others. In this case, students feel that working on an online test cannot be rushed because it is pursued by time and with limited time. It may happen because they are used to using paper tests or manual. However, in online assessment you have to submit your assignment before the deadline because when the time is over you cannot submit your task anymore. That is one of the challenges of online assessment in Google Classroom.

The second reason is about the internet connection, the second challenge faced by students is about internet signals, where most of them feel annoyed when they have to do the test and at that time the internet signal is bad so students cannot answer a few questions or even fail to submit the answer. This obstacle made student feel upset because they have to re-do the test etc. The bad connections also caused by the student were run out of quota. It was confirmed by the student, they must prepare everything from the computer, student readiness, and internet signals when going to work on an online test, students must go to places where the signal is fast and not slow or bad signals, and enough quota. So that, student can do online tests comfortably without obstacles with the internet signals.

The third is about the application problem, Actually, this is not because of the problem of the application, it is because students feel confused when using online tests in Google Classroom. This is possible because before the students had never conducted tests online, they were confused. But to use Google Classroom itself they feel very easy. Furthermore, sometimes the students found out that the App is suddenly close or out automatically. According to Alruwais, Wills, and Wald (2018) one of the challenges of online assessment is students still not experience to use the computer and the online assessment process. As previously explained, they find it easy when using the online test application in Google Classroom. That was happened because their phone or computer was corrupted. 
Based on the explanations above, the student faced some challenges in doing an online assessment, it happened because of few factor such as internet, time, and the system. However, the students are enjoyed and agreed that online assessment is more effective than paper assessment. This is one of the future innovations that the millennial have to adapt with.

\section{CONCLUSIONS AND SUGGESTIONS}

Based on the result in chapter four about the students' perception and the students' challenges in doing an online assessment in Google Classroom, the researcher have made several conclusion as follow:

1. The student have positive toward the implementation of online assessment. That was happened because of several reasons, one of them is about the effectiveness. Online assessment in Google Classroom saves their time. It is more efficient because the students are to do the test everywhere without paper.

2. Even though, they have positive perception toward the use of online assessment in Google Classroom, there are still some challenges they faced when working on online tests. Based on the result of the research, it can be concluded that the challenges they face are about time, internet signal, and so on.

After understanding the finding of this research, there are several suggestions that can be addressed for the English teacher and future researcher.

1. The teacher/lecturer

This study indicated that the use of online assessment in Google Classroom can be an effective way to identify the students' progress. This finding indicated that the students have positive responses toward the use of online assessment in Google Classroom. They also expect other teacher or lecturer can also apply Google Classroom for assessing their progress.

2. Future researcher

For the future researcher, they can conduct similar research with focusing on identifying students' perception of online assessment use. Particulary, they do not to identify the use of online assessment in Google Classroom, they can identify online assessment in different LMS such; Edmodo, Moodle, Schoology and many more. The features maybe different from Google Classroom but the purpose is the same. The future researcher could also add another instrument for example do the observation or interviewing the students about their perception.

\section{REFERENCES}

Alwurais, Nuha - Gary Wills - Mike Wald. (2018). Advantages and Challenges of Using e-Assessment.International Journal of Information and Education Technology.Vol. 8 No. 1.

Adams, Dennis - Mary Hamm (2013). Demistify Math, Science and Technology Creativity, Innovation and Problem Solving Second Edition. United Kingdom: Rowman\& Littlefield Education. 
B. Diaz, Sofia - Jose A. Diniz - Lentios J. Hadjileontiadis (2014). Towards an Inteligent Learning Management System Under Blended Learning. Switzerland: Spinger.

Chen, Yining, and Leon B Hoshower. "Student Evaluation of Teaching Effectiveness: An Assessment of Student Perception and Motivation." Carfax Publishing. Vol. 28 No. 1, 2003.

Kats, Yefim (2010). Learning Management Systems Technologies and Software Solutions for Online Teaching: Tools and Application. United States of America: IGI Global.

L. Schacter, Daniel - Daniel T. Gilbert - Daniel M. Wegner. (2009). Psychology. United States of America: Worth Publishers.

Ozden, M Yazar - Ismail Erturk - RefikSanli (2004).Student Perception of Online Assessment.Journal of Distance Education Revue De L'éducation À Distance. Vol. 9 No. 2. 2004. 77-92 